\title{
LA CARIDAD PASTORAL Y JUAN DE ÁVILA
}

\author{
Lorenzo Orellana Hurtado ${ }^{1}$
}

DOI: https://doi.org/10.52039/seminarios.v57i201-202.335

\section{LOS TÉRMINOS}

El título de la presente reflexión nos invita a observar la caridad pastoral en la vida de san Juan de Ávila. «Caridad pastoral» es una expresión reciente que ilumina como ninguna otra el ministerio del presbítero. Su primer término, «caridad», ha llegado a definir a Dios: Deus caritas est. Dice Benedicto XVI: «EI amor hace de la vida una obra de arte y de cada hombre un artista extraordinario» ${ }^{2}$. El amor cohesiona y plenifica la tarea pastoral del sacerdote. El segundo término, «pastoral», encierra todo lo que los presbíteros han de buscar, realizar, sufrir y gozar en su ministerio. Todo, al estilo de Cristo, Buen Pastor, modelo y sustento de la caridad pastoral.

Y decimos que esta expresión es reciente porque su difusión crece a partir del Vaticano II. En la Lumen Gentium, Christus Dominus y Presbiterorum Ordinis encontramos sus principales citas. El número 14 de la $\mathrm{PO}$, que trata de la armonía y vida de los presbíteros, es clave: «Los presbíteros conseguirán la unidad de su vida uniéndose a Cristo en el conocimiento de la voluntad del Padre y en el don de sí mismos por el rebaño que les ha sido confiado».

No se puede sintetizar mejor. Unión con Cristo y donación de sí mismos. Unión con Cristo, porque Cristo es la fuente, origen y razón de la vida del sacerdote. Unión, porque sólo en Él se manifiesta plenamente la voluntad del Padre. «Y así -prosigue PO-, desempeñando el oficio de buen pastor, en el mismo ejercicio de la caridad pastoral hallarán el vínculo de la perfección sacerdotal que reduzca a unidad su vida y acción» ${ }^{3}$. El vínculo de la perfección sacerdotal, su santificación y unidad de vida y acción, lo hallarán los sacerdotes en el mismo ejercicio de la caridad pastoral, es decir, en la entrega al prójimo, la lglesia y el Mundo al estilo de Cristo, Buen Pastor.

Dos actitudes, dos miradas conforman, pues, la vida del presbítero: una al Buen Pastor y otra a las ovejas. La primera, para que el amor del Buen Pastor

1. Sacerdote de la Diócesis de Málaga (España). Doctor en Teología.

2. Palabras del papa Benedicto XVI, durante la inauguración de una exposición artística en su honor, con motivo del 60 aniversario de su ordenación sacerdotal.

3. Y el Directorio: Ministerio y vida de los presbiteros, en su n. ${ }^{\circ} 43$, dice: «La caridad pastoral constituye el principio interior y dinámico capaz de unificar las múltiples y diversas actividades del sacerdote y-dado el contexto socio-cultural en el que vive- es instrumento indispensable para llevar a los hombres a la vida de la gracia». 
resplandezca en sus vidas; la segunda, para que cuiden de la grey con entrañas de buenos pastores. Dos actitudes que Juan de Ávila no solo vivió, sino que quiso que vivieran todos los sacerdotes.

\section{PRIMERA EXPERIENCIA}

La primera vez que entré en un museo era yo niño. Lo que más me llamó la atención fue observar cómo un hombre miraba aquel cuadro. Se quedaba observándolo un rato y después trazaba unas líneas en el lienzo que tenía en un caballete. Volvía a levantar la vista y, por un instante, quedaba absorto, casi en éxtasis. Su actitud me llamó tanto la atención que le pregunté:

- ¿Por qué lo mira así?

Se volvió hacia mí, sonrió y dijo:

-Niño, es que quiero recordar la seguridad de sus trazos y la fuerza de su color.

La caridad pastoral pide que los trazos y color de Cristo, se reflejen en la vida del sacerdote lo más fielmente posible. PO 2, afirma: «Los presbíteros, por la unción del Espíritu Santo, quedan sellados por un carácter particular, y así se configuran con Cristo sacerdote». Los términos configurados o conformes con Cristo arrancan del Nuevo Testamento. San Pablo, en Rm 8, 29, dice a los cristianos que Dios «los predestinó a ser conformes a la imagen de su Hijo» ${ }^{4}$.

El documento Espiritualidad Sacerdotal y Ministerio, de la Comisión Episcopal del Clero, afirma:

El presbítero sigue e imita a Cristo cumpliendo el oficio de buen pastor, es decir, ejerciendo la caridad pastoral. Todo amor verdadero está hecho de adhesión e identificación. Por la adhesión «entramos» en la persona querida. Por la identificación, la persona querida «entra» en nosotros. El presbítero ama a Cristo con amor de identificación reproduciendo en su vida las actitudes y comportamientos del Buen Pastor ${ }^{5}$.

Juan Pablo II, que recoge las enseñanzas del Concilio sobre los sacerdotes en Pastores dabo vobis, escribe que esa identificación con Cristo, ese carácter particular que une al sacerdote con Cristo es una «ligazón ontológica específica» (PDV 11). Es decir, desde la misma Ordenación el sacerdote queda constituido e impelido para configurarse con Cristo.

4. Conformes, synmorphoi. Morphé significa forma, figura, y de ahí resulta que hemos de conformarnos, configurarnos según el modelo, Jesucristo. Cf. M. GuERRA, La conformación con Jesucristo. Simposio sobre Espiritualidad del presbitero diocesano secular, Madrid 1987.

5. Espiritualidad Sacerdotal y Ministerio. Comisión Episcopal del Clero, Edice, 63. 
Y Juan de Ávila pide a los sacerdotes que se transformen en Cristo, siendo tan conformes que no sean dos. Tan conformes, tan con los mismos trazos y forma de Cristo, que no sean dos, sino que sean configurados, identificados con Él, porque el Padre quiere su disponibilidad para que el Hijo resplandezca en todos.

Y Cristo resplandece en los sacerdotes cuando ellos «entran» en Él con amor de adhesión, más aun, cuando Él «entra» en cada uno de ellos con amor de identificación. Entonces la unión con Cristo es el alma de la caridad pastoral y lo que da unidad a todo su ministerio ${ }^{6}$.

Pero los hombres somos hijos de nuestra época y nos desarrollamos en un contexto histórico. Por eso, si queremos conocer la luz y enseñanzas que se desprenden de la vida de Juan de Ávila será bueno que nos acerquemos a él.

Vamos a hacerlo teniendo como falsilla lo que propone en el Audi filia cuando habla de la necesidad del propio conocimiento: «Tenéis, pues, este orden en el mirar: que primero os miréis a vos, y después a Dios, y después a los prójimos... Porque no hay peor engaño que el ser engañado uno en sí mismo» ${ }^{7}$.

\section{QUE PRIMERO OS MIRÉIS A VOS}

La vida humana es más rica cuanto mejor conoce sus límites y valores, sólo eso evita que uno pueda ser engañado en sí mismo.

Primero que os miréis a vos. A vos, para conoceros, pues como dice Juan de Ávila: No hay edificio seguro sino es hecho sobre hondo conocimiento (Carta 12, 38). Todo el edifico sacerdotal se construye sobre la persona que somos. $Y$ si estamos llamados a ser responsables de una comunidad y hombres de comunión, entonces «es necesario que el sacerdote plasme su personalidad humana de manera que sirva de puente y no de obstáculo a los demás en el encuentro con Jesucristo» (PDV 43).

Y para que el presbítero no sea obstáculo, sino puente para quienes buscan a Dios, es necesario «no sólo una justa y necesaria maduración y realización de sí mismo, sino también en vistas de su ministerio, los futuros presbíteros deben cultivar una serie de cualidades humanas necesarias para la formación de personalidades equilibradas, sólidas y libres, capaces de llevar el peso de las responsabilidades pastorales» (PDV 43). Aún más, las cualidades personales y la formación humana la han de completar con una formación espiritual que les ayude a vivir íntimamente unidos a Dios.

6. Si la «semilla» es la Palabra de Dios, el amor de adhesión nos ha de llevar a «entrar» en ella conociéndola, estudiándola, amándola y orando con ella. Y ese es el camino para que ella «entre» en nosotros y nos posea el amor de identificación.

7. Audi filia, I, 462 n. $1335 \mathrm{~s}$ 
Ya don Miguel de Unamuno afirmaba que la espiritualidad clásica española había arrancado del conocimiento introspectivo. Y es verdad. Pero ese conocimiento no era mera reflexión o estudio psicológico, sino ejercicio de purificación y oración que vaciaba de sí al orante y lo llenaba de Dios. Por eso, Juan de Ávila escribe en la carta 54: «Conviene, pues, no mirarnos a solas; sino que, mientras nos miramos y nos lloramos, alcemos los ojos hacia arriba, considerando a Cristo Nuestro Señor, el cual está tan lleno de misericordia y remedio».

Y si todo conocimiento supone una búsqueda, esfuerzo, tensión, entrega y gozo, éste aun más, pues se juega uno el ser o no ser. Veamos cómo realiza Juan de Ávila esa búsqueda, conocimiento y entrega de sí mismo.

\section{TIEMPO POCO PROPICIO}

Sabemos que desde el concilio de Constanza (1414-1418) al de Trento (15451563), los libelos de carácter satírico-burlón contra los clérigos fluyeron sin cesar. Es verdad que el estado clerical no puede ocultarse a la mirada de los contemporáneos. Y es verdad que el gran pontífice Inocencio III hacía siglos que había exclamado con tristeza: omnis in populo corruptela principaliter procedit a clero. Las aguas de la historia llegaron harto turbias al siglo XVI. Y aunque también trajeron deseos de reforma que habían alimentado obispos, sacerdotes, religiosos y pueblo fiel, estos deseos menguaron en el clero secular, porque la selección y formación de los candidatos era tan pobre que muchos no entraban por la puerta, sino, como decía nuestro santo, saltaban por vallas y bardales.

En estas circunstancias aparece Juan de Ávila, quien a los 14 años marcha a Salamanca, seguramente para estudiar leyes. Pero sin que conozcamos el motivo abandona la ciudad y vuelve a su pueblo: Almodóvar del Campo (Ciudad Real), donde tras un tiempo de búsqueda, en el que vive apartado en su casa, marcha a la joven universidad complutense.

Melquíades Andrés dice que Alcalá representaba el último grito de la modernidad porque «había dado un salto gigante en el terreno de la metodología y de la atención al alumno». A la misma hora -cuenta-, ofrecía la posibilidad de que «cada matriculado escogiese un autor nominal (Gabriel Biel), escotista (Escoto), o tomista (Santo Tomás de Aquino)». A este reparto de cátedras, Melquíades Andrés lo llama «método teológico de las tres vías». «Y esto obligaba a los teólogos españoles a saber distinguir con precisión los misterios revelados de las explicaciones escolásticas, las coincidencias y diferencias con los humanistas, alumbrados, erasmistas, protestantes y místicos» ${ }^{8}$.

Este es el ambiente de estudio en el que se prepara nuestro santo. Él asiste a las clases de Juan de Medina, catedrático de teología nominal. Y termina sus

8. Ibid., 32. 
estudios con el título de bachiller, al tiempo que ha ido cultivando una serie de cualidades humanas necesarias para la formación de una personalidad equilibrada, sólida y libre, capaz de llevar el peso de las responsabilidades pastorales.

Se ordena sacerdote. Celebra su primera misa en Almodóvar donde se plantea su futuro desde la radicalidad del seguimiento de Cristo. Vende sus bienes patrimoniales (sus padres habían fallecido). Reparte el dinero entre los pobres y decide partir como misionero hacia el Nuevo Mundo. Marcha a Sevilla, desde donde zarpan las naves. Se pone en contacto con fray Julián Garcés, dominico, recién nombrado primer obispo de Tlaxcala (México) que prepara una expedición de misioneros ${ }^{9}$. Pero se le cierra el paso: Juan no pertenece a ninguna orden religiosa y, además, procede de conversos. No puede embarcar.

\section{SUS INDIAS, ANDALUCIÁ}

Sus amigos le dicen que "sus Indias están en Andalucía», y comienza su andadura apostólica por Sevilla y comarcas.

Su forma de predicar: bíblica, directa y exigente, llama la atención y nacen las primeras críticas. Pronto es acusado ante el tribunal de la Inquisición. Y el tribunal, obligado como estaba, lo investiga y encarcela. En la cárcel se pasa casi un año. No se le condena. Su sentencia absolutoria se firma el 5 de julio de 1533. En ella, además de mandarle que se modere en el hablar, se dicta:

Visto por Nos, los inquisidores apostólicos, el presente proceso, sentenciamos que el promotor fiscal no probó su intención, como la debía probar, y por lo mismo la damos por no probada, y que el bachiller Juan de Ávila probó sus excusas y defensas, y por lo mismo las damos por bien probadas, y que debemos absolver, como absolvemos al dicho bachiller de la instancia de este juicio.

Pero la cárcel, que a otro hubiera hundido o amargado, a Ávila se le convierte en un presente de Dios. Dedica su tiempo a la oración y a la traducción del Contemptus mundi, y allí encuentra el mejor conocimiento de Cristo y de sí mismo.

Años más tarde, Fr. Luis, admirado por el conocimiento tan singular que tiene del misterio de Cristo, le pregunta cómo lo ha adquirido. Esto es lo que cuenta el de Granada:

Tratando una vez familiarmente conmigo de esta materia, me dijo que en este tiempo (el de la cárcel) le hizo nuestro Señor una merced que él estimaba en gran precio, que fue darle un muy particular conocimiento del misterio de Cristo: esto es, de la grandeza de esta gracia de nuestra redención y los grandes tesoros que te-

9. Fray Julián Garcés fue el primer obispo que hubo en la Nueva España y en la diócesis de Tlaxcala. Formó a no pocos religiosos que allí profesaron. Gran defensor de los indios. Es célebre la carta que escribe al Papa, Paulo III, pidiendo la declaración formal de la capacidad de los indios para recibir los sacramentos como verdaderos hombres en todos los sentidos. 
nemos en Cristo para esperar, y grandes motivos para alegrarnos en Dios y padecer trabajos alegremente por su amor: y por eso tenía él por dichosa aquella prisión, pues por ella aprendió en pocos días más que en todos los años de su estudio.

Fray Luis, que recordaba vivamente lo que le contara el Maestro ${ }^{10}$, al rememorar sus palabras transcribe tal aire de precisión, conocimiento y gozo que, según le dice, «tenía por dichosa aquella prisión». Y a partir de esta experiencia ya no hablará de oídas, sino desde dentro. Su identificación con Cristo va a ser el alimento de su amor y entrega. Saldrá de la cárcel con el ideal apostólico perfilado: llevar el conocimiento de Cristo a aquella sociedad concreta, dándose a todos, y muy de veras a los sacerdotes, pues los sacerdotes son principalmente diputados para la honra y contentamiento de Dios ${ }^{11}$.

\section{DESEO Y DETERMINACIÓN}

Pero la realidad de la España del siglo XVI, por un lado, y el luteranismo que había barrido la diferencia entre el sacerdocio de los fieles y el sacerdocio ministerial, por otro, no van a facilitar la vida de Juan de Ávila. Los frentes que se le presentan exigen más estudio, más oración y más trabajo. Así que sale de la cárcel determinado a gastarse y desgastarse por Cristo y por la renovación de su Iglesia.

La absolución inquisitorial le ayuda en su propósito, pues aumenta su prestigio y pronto se le unen los primeros sacerdotes. Pronto, también, descubre la necesidad de alcanzar el doctorado. Y hubo de doctorarse. ¿Dónde? No se sabe, pero en 1538 comienzan a llamarle maestro, es decir, doctor ${ }^{12}$.

Juan de Ávila tiene claro que la trabazón de su vida ha de ser: estimar a Dios en mucho y de ahí estimar a los trabajos en poco. Su caridad pastoral arranca del amor de Dios. Y su trabajo sacerdotal, como buen conocedor de san Agustín, sabe que es amoris officium. Por eso, en la carta 17, dice: «Fortísima cosa es un corazón determinado a querer a Dios; porque, como entiende que puede alcanzar a este que desea, no teme meterse por lanzas, teniéndose por cumplidamente dichoso con sólo este bien que alcance, aunque sea a trueco de todo lo que le puedan pedir» ${ }^{13}$.

10. Fray Luis en carta a sor Ana de la Cruz, condesa de Feria, dice del Audi, filia: «También podré yo decir que lo tengo en la cabeza por haberlo leído muchas veces; $y$, cuando lo leo, paréceme que veo vivo al Padre en aquellas letras muertas, mayormente acordándome cuántas veces platicó conmigo muchas de éstas».

11. L. Sala Balust-F. Martín Hernández, Obras Completas, Madrid 1970, III, Plática 1, 235s.

12. El primer documento que así lo identifica pertenece al cabildo de Granada que encomendó «al maestro Ávila» predicar el sermón de la bula cruzada el 1 de marzo de ese año. Y, al año siguiente, el doctor Rodrigo López entregó la gestión del colegio de Baeza a Juan de Ávila, «maestro en sagrada teología, residente en Granada».

13. Carta 17, 31. 
Un corazón determinado a querer a Dios. La determinación es lo primero, pues mucho tiene andado del camino el que tiene buena gana de andar (Carta 63). Determinado a querer a Dios, y por eso dice: «Es tal esta bendita caza sobre toda bienaventuranza bendita, que no se deja prender sino del corazón que arde con su amor» ${ }^{14}$. «Amémoste, pues, y conozcámoste por el conocimiento que brota del amor» ${ }^{15}$.

Su corazón está decidido a querer a Dios, aunque sea a trueque de lanzas y de todo lo que se le pueda pedir, porque vivir enraizado en lo que da unidad a la vida no es sólo tarea, sino gozo. Por eso, vivir desde el amor de Dios, desde el conocimiento que brota del amor y el servicio a todos, y así renovar la Iglesia, es su mayor deseo. Ese es su empeño. Por ahí le lleva la caridad pastoral. Por eso, cuando se detiene ante el amor de Dios escribe: «Más mueve el corazón el amor que los beneficios; porque el que hace a otro beneficio, dale algo de lo que tiene; mas el que ama, da a sí mismo con lo que tiene, sin que le quede nada por dar» ${ }^{16}$.

El Maestro ha colocado en primer lugar su determinación de amar a Dios. A Dios, piélago de amor. "A Dios, que es caridad y el que permanece en la caridad permanece en Dios y Dios en él» (1 Jn 4, 16). A Dios, que se nos ha dado a sí mismo en su Hijo, Cristo Jesús. Esto es lo que escribe a un predicador: «Ensanche vuestra merced su pequeño corazón en aquella inmensidad de amor con que el Padre nos dio a su Hijo; y con él nos dio a sí mismo, y al Espíritu Santo y todas las cosas ${ }^{17}$. Y tanto ha ensanchado él su corazón que, ante el amor del Padre manifestado en su Hijo por el Espíritu, Juan de Ávila queda sobrecogido y se pregunta: «¿Quién constriñó a Dios a hacerse hombre? No otro sino el amor».

No otro sino el amor, y subraya que es el amor de Dios el que se nos da y salva en Cristo. Y su espiritualidad se hace cristocéntrica. Y su sentir y vivir se sustentan en el amor del Padre manifestado en Cristo, imagen de Dios invisible, que se hace hombre por amor, que se hace Buen Pastor por amor. Y con un amor tan único que «no hay lengua que lo pueda explicar, porque como san $\mathrm{Pa}$ blo dice, «la caridad de Cristo excede todo conocimiento y sentido»... Porque no nace el amor de Cristo de la persona que hay en nosotros, sino de la que Él tiene, que es mirar a su Eterno Padre» ${ }^{18}$.

Por eso, quien considera este amor: «No se puede esconder de tu amor porque haces fuerza a los corazones, como dice el Apóstol: 'La caridad de Cristo nos hace fuerza' $(2$ Cor 5,14$) »^{19}$.

14. Sermón 23,157

15. Carta 64,1129

16. Tratado del amor de Dios, 364.

17. Carta 160, 14ss.

18. Tratado del Amor de Dios, n. 4

19. Ibid., n, 9 
Y a vivir ese amor, que da consistencia y unidad a su vida es a lo que se entrega Juan de Ávila, y por eso:

-Llena su vida con la lectura y estudio de la Sagrada Escritura, porque, como dice $\mathrm{PO}$, «los presbíteros tienen por deber primero el de anunciar a todos el evangelio de Dios», y él recomienda: «sed amigos de la Palabra de Dios, leyéndola, hablándola, obrándola» ${ }^{20}$.

- Llena su vida con la oración, de la que llega a ser un gran maestro, pues no se puede conocer y amar a Dios si no es por el camino de la oración ${ }^{21}$.

-Y la llena con la entrega incansable a la caridad, a la instrucción del pueblo y a la formación de los sacerdotes ${ }^{22}$.

Sus biógrafos cuentan que el Maestro se sabía la Biblia de memoria, que vivía de oración y que no sabrían decir si salvó más almas con sus palabras o con su caridad. En la carta 57 escribe: «Lea, ore y comulgue, y tenga caridad, y estará Dios con usted». Por todo esto, fue fiel a su consejo: que primero os miréis a vos, no a solas, sino alzando los ojos y considerando a Cristo, para construir la vida desde las cualidades personales y la misericordia divina.

\section{SEGUNDA EXPERIENCIA}

Que cada uno ha de vivir su unión con Cristo, lo sabemos. Que nuestra unión con Cristo se expresa en el ejercicio de nuestro ministerio, también lo sabemos. Y que según sea nuestra oración, así será nuestra fe y caridad pastoral, es algo que experimentamos cada día. Valga una mínima experiencia personal.

Después de seis años en Venezuela, en una parroquia de $1200 \mathrm{~km}$ cuadrados para mí solo, fui enviado a Melilla. En Melilla, con una extensión de $13 \mathrm{~km}$ cuadrados, había dos parroquias regentadas por padres capuchinos, otras dos por padres paúles y una por el clero secular a la que yo llegaba. El primer día sentí tal sensación de soledad y agobio que casi me dolía el pecho y se me hacía difícil orar. La segunda mañana, en una ciudad donde no conocía a nadie y mi antecesor había tenido que marcharse antes de mi llegada, me dirigí al puerto. Hacía dos días que por allí había arribado a la Rusadir fenicia, y ahora, como si quisiera desandar el camino y volver a Málaga, mis pasos se encaminaban de nuevo hacia el puerto. Traspasé la verja y observé el dique que se erguía y alargaba hacia la bocana. Descubrí los escalones que ascendían hacia su altura

20. Carta 86, 194. En Espiritualidad Sacerdotal y Ministerio: «El carisma ministerial consiste en engendrar la comunidad cristiana extrayendo de la Palabra el sustento y el vigor para construir la Iglesia». o.c., 50.

21. Espiritualidad Sacerdotal y Ministerio: «La oración del presbítero adquiere, por efecto de la caridad pastoral, tonalidad netamente apostólica», 69.

22. Idem. "Todo es o condición o componente o derivado o, al menos, compatible con la caridad pastoral. En consecuencia, todo está ceñido y coloreado, es decir, modificado por la caridad pastoral», 64. 
y comencé a subirlos como un autómata. Anduve muy despacio, observando allá abajo el ir y venir de los coches y el movimiento de las gentes que entraban y salían de la estación de embarque. Elevé la mirada y me topé con el azul del mar. Me detuve absorto, contemplándolo. Recordé que mi acción de gracias, tras la misa, había estado cargada de desgana. Así, que pedí al Señor que me ayudase a encontrar la alegría que se me iba. Me senté y cerré los ojos queriendo hacer silencio. Recuerdo que me encomendé al Espíritu Santo diciendo: "Te doy lo que tengo; te doy esta tristeza tonta y este estar aquí, frente al mar». Abrí los ojos y miré la constancia del Mediterráneo. No llevaba mucho rato contemplando aquella belleza azul, cuando advertí que tenía tonalidades y que, agua adentro, se distinguía una corriente de un intensísimo añil. Era como un pequeño río dentro del mar, como una vena que recorriese sus entrañas marinas. Y vi claro: mi vida, que en esos momentos me parecía desorientada, era llevada como aquella pequeña corriente única por el mar de Dios. Me encontraba en el mar del amor de Dios. Sólo tenía que dejarme llevar. Y comencé a adorar y agradecer. $Y$ me acordé del pasaje de los Magos cuando vieron al Niño y le adoraron y ofrecieron sus dones. Y aquella mañana supe que mi belén había sido el puerto de Melilla donde se me había ofrecido la huella de Dios, la huella de Cristo, Buen Pastor, y yo había comenzado a donarle mi presente. Y entonces, recordé una frase de Juan de Ávila que nos había enseñado el padre espiritual, don Alberto Planas: ¿Quieres que el Señor te dé su luz y te enseñe? Ten oración, pide, que darte ha. Todos los engaños vienen del no orar.

\section{DEspuÉs a Dıos}

La segunda mirada que pide el Maestro Ávila es a Dios. A Dios, porque todo lo que es está colgado de su ser.

Después a Dios «manifestado en Cristo». "Faz del eterno Padre». "Lazo entre el Padre y nosotros». "Fuente de gracia». "Verdadero Dios y verdadero hombre». Este es el espejo en que os habéis de mirar (AF 69, 7091). "Porque el Padre Eterno puso un Medianero entre nosotros y Él para que por su medio alcanzásemos misericordia» ${ }^{23}$.

Y si PO utiliza la alegoría del Buen Pastor para hablar de la caridad pastoral, PDV nos recuerda que «los presbíteros son llamados a prolongar la presencia de Cristo, único y supremo Pastor, siguiendo su estilo de vida y siendo como una transparencia suya en medio del rebaño» ${ }^{24}$.

Mirada a Dios en Cristo, puesto que Él les alcanza la misericordia para que los sacerdotes lleguen a ser una transparencia suya. Para que se identifiquen

23. Carta 222, 262.

24. PDV, 15. 
con el Buen Pastor, que se entrega al cuidado de sus ovejas, y las conoce, y llama por su nombre, y alimenta, defiende, guía, busca y da la vida por ellas. Este ha de ser el ideal del sacerdote. Este el camino, pues así es como se santifican y viven en plenitud y armonía. Y así será como la caridad pastoral vincule sus vidas y les lleve a aquello que decía san Agustín, «sea tarea de amor apacentar el rebaño del Señor».

$Y$ aunque hoy parece que una ola de cansancio espiritual recorre nuestra vieja Europa, el ejemplo de Juan de Ávila, nos sigue iluminando.

El Maestro Ávila decía: Abásteos Dios (y era una adelantado del «sólo Dios basta», de santa Teresa), abásteos Dios... que es sapientísimo Bien.

\section{TERCERA EXPERIENCIA}

Hace ya tiempo, una tarde, frente a un cortijo vacío, me comentaba un campesino:

-Aquí, hasta hace poco, hubo grandes rebaños de ovejas. Pero tuvieron que salir de ellas porque ya nadie quiere ser pastor.

Ante mi cara de ignorancia, añadió:

-Sí, ser pastor es un mal oficio. ¿Usted no sabe que el pastor ha de vivir al ritmo de las ovejas? Ellas son las que mandan: el pastor ha de acoplarse a su paso, ha de caminar todo el día tras ellas, ha de descansar cuando ellas sestean, y ha de volver al redil cuando anochece.

Se detuvo, me miró y dijo:

-Hoy, nadie quiere un oficio tan esclavo.

Recuerdo que tras aquel comentario me asaltó la imagen del Buen Pastor. El Buen Pastor que vuelve cansado por el peso de la jornada tras las ovejas, y que, de nuevo, ha de desandar los caminos en busca de la perdida.

\section{MÁS DIFíCIL QUE EVANGELIZAR PAGANOS}

El amor a Dios lleva a Juan de Ávila, tras la salida de la cárcel, a entregarse por aquella sociedad que le ha encarcelado. «Tarea más difícil que evangelizar paganos», le dicen sus amigos.

En 1535 le llama el obispo de Córdoba, Fr. Álvarez de Toledo. Acude. Se hospeda en el hospital. Entabla amistad con Fr. Luis de Granada y con el nuevo obispo don Cristóbal de Rojas (a quien dirigirá, más tarde, las Advertencias para el Concilio de Toledo). Crea centros de estudio, presta especial atención al clero, al que instruye y explica la carta a los Gálatas. En el Alcázar viejo se le reúnen más de veinte sacerdotes con los que comparte sus inquietudes e inicia las misiones populares. Su biógrafo Luis Muñoz nos ha transcrito lo que pedía el Maestro a quienes se embarcaban en estas tareas: 
Díjoles que era su intento se repartiesen por diferentes partes, predicando la palabra divina, moviesen los pueblos a penitencia, contrición y lágrimas, les oyesen en confesión y administrasen el sacramento de la Eucaristía; finalmente, les ayudasen en todas las cosas de su salvación.

En 1536 le llama don Gaspar de Ávalos, Arzobispo de Granada, y de nuevo en camino. En Granada se entrega a la predicación y sus palabras hacen que Juan Cidad cambie su nombre por el de Juan de Dios ${ }^{25}$. Su amor a Dios, manifestado en la caridad pastoral no tiene límites: la predicación, la catequesis, la dirección espiritual y la fundación de colegios le lleva a todas partes.

En 1538, impulsado por su celo, escribe a unos discípulos, y, a partir de este momento sus devotos se multiplican y deberá sacar tiempo para aconsejar, iluminar y dirigir, desde gente sencilla hasta obispos, desde laicos hasta sacerdotes, frailes, matrimonios, amigos, villas o cabildos. Sus cartas -algunas verdaderos tratados- se cuentan por cientos. $Y$ todo, porque su caridad pastoral es «aquella virtud con la que nosotros imitamos a Cristo en su entrega de sí mismo y en su servicio. No es sólo aquello que hacemos, sino la donación de nosotros mismos lo que muestra el amor de Cristo por su grey. La caridad pastoral determina nuestro modo de pensar y de actuar, nuestro modo de comportarnos con la gente. Y resulta particularmente exigente para nosotros» (PDV 23).

La caridad pastoral resulta particularmente exigente porque «Cristo es el principal sacerdote y fuente de nuestro sacerdocio» ${ }^{26}$; «por ello, nuestra representación ha de ser tan verdadera, que el sacerdote se transforme en Cristo» ${ }^{27}$; "ya que por su gracia nos eligió» ${ }^{28}$ "para ser pastores criadores del ganado, que los apacienten en los pastos de ciencia y doctrina... y, aunque sea con derramar sangre y dar la vida, como hizo Cristo, y dijo que este tal es buen pastor ${ }^{29}$. Con estas palabras, el Apóstol de Andalucía traza el arco de la caridad pastora ${ }^{30}$ : el sacerdote es un hombre vocacionado del que Dios en Cristo es fuente y fin. Él lo elige para que actúe en su nombre. Lo ordena para sea pastor de su rebaño y lo apaciente con ciencia y doctrina. Por eso su misión y gozo no es otro que identificarse con Cristo y, si preciso fuera, dar su sangre y vida como hizo el Buen Pastor.

25. Su gran entrega a la predicación consta ya en la primera edición de sus obras: Obras del Padre Maestro Juan de Ávila, predicador en el Andalucía. Luis Muñoz, su primer biógrafo, titula su libro: Vida y virtudes del venerable varón el Padre Maestro Juan de Avila, predicador apostólico. Y fray Luis de Granada: Vida del Padre Maestro Juan de Ávila y partes que ha de tener un predicador del evangelio.

26. Tratado sobre el sacerdocio, n. ${ }^{\circ} 10$.

27. Ibid., n. ${ }^{\circ} 26$.

28. Sermón $15,59 \mathrm{~s}$

29. Advertencias... I, n.6; cf. Sermón 81 , 88 s; aunque este texto se refiere a los prelados, perfectamente es extensible a los sacerdotes.

30. «Ha de arder en el corazón del eclesiástico un fuego de amor de Dios y celo de almas», Plática $7^{\mathrm{a}} 62 \mathrm{ss}$. Expresión que tenían para hablar de la caridad pastoral. «Si de veras nos quemase las entrañas el celo de la casa de Dios», cf. Carta 208, 11 s. 
Y es que, como dice PO 13: «Los presbíteros conseguirán de manera apropiada la santidad ejerciendo sincera e incansablemente sus funciones en el Espíritu de Cristo». Pues «mediante la Ordenación habéis recibido el mismo Espíritu de Cristo, que os hace semejantes a Él, para que podáis actuar en su nombre y vivir en vosotros sus mismos sentimientos» (PDV 33). Vivir sus mismos sentimientos, he ahí el objetivo central de esta segunda mirada. «Suya es la obra; ministros suyos somos nosotros» (Carta 136). Ministros por el sacramento del Orden que es un carisma por el que quedamos unidos a Cristo sacerdote. Es una vitalidad o como dice Mons. Uriarte, «es una cantera inagotable, un sedimento activo, un yacimiento permanente de la caridad pastoral, plantado en nuestro mismo corazón por la sagrada ordenación que compartimos con todos los presbíteros de la diócesis y, especialmente, con el Obispo» ${ }^{31}$.

Por ello, Juan de Ávila se queja diciendo: «¡Cuán mal te sabemos agradecer el poder que has dado a los sacerdotes y cómo los has hecho despenseros de tus merecimientos!» (Sermón 58, 157ss).

Despenseros de sus merecimientos, sobre todo del amor hecho perdón, palabra y eucaristía. Esta verdad recorre la historia de la espiritualidad sacerdotal. Gregorio Magno la expresaba así: «Es necesario que cuando celebremos nos inmolemos nosotros mismos a Dios con corazón contrito, pues quienes celebramos los misterios de la pasión del Señor debemos imitar lo que hacemos, sólo cuando hagamos de nosotros mismos una víctima ofreceremos a Dios un sacrificio que sea en beneficio vuestro». Por su parte, Mons. Uriarte señala: «Cuando celebramos la Eucaristía y representamos sacramentalmente a Cristo en esa Eucaristía, somos asociados con Él a la dinámica de esta doble y única entrega: de la entrega pastoral a los hermanos, de la entrega filial a Dios. En cada eucaristía somos arrastrados por Él en ese doble y único movimiento de la caridad pastoral» ${ }^{32}$.

Pastores dabo vobis afirma al respecto: "La caridad pastoral, que tiene su fuente específica en el sacramento del Orden, encuentra su expresión plena y alimento supremo en la Eucaristía... La caridad pastoral fluye ciertamente, sobre todo, del sacramento eucarístico, que es, por ello, centro y raíz de toda la vida del presbítero, de suerte que el alma sacerdotal se esfuerce en reproducir en sí misma lo que hace en el ara sacrificial» (n. 23). Y Juan de Ávila: «El sacerdote en el altar representa, en la misa, a Jesucristo Nuestro Señor, principal sacerdote y fuente de nuestro sacerdocio; y es mucha razón que quien le imita en el oficio, lo imite en los gemidos, oración y lágrimas... En este espejo sacerdotal se ha de mirar el sacerdote, para conformarse en los deseos y oración con Él; y ofreciéndolo delante del acatamiento del Padre por los pecados y remedio del mundo, ofrecerse también a sí mismo, hacienda y honra y la misma vida, por sí y por todo el mundo; y de esta manera será oído, según su medida y semejanza con Él»»33.

31. J.M. URIARTE, Ministerio presbiteral y espiritualidad, San Sebastián 2003, 63.

32. URIARTE, O.C., 65. 
Será oído, según su medida y semejanza con Él. Con Él, que se hace palabra y pan. Con Él que se hace palabra, y por eso «el carisma ministerial instaura en el presbítero una estrecha relación con la Palabra. Vive de ella y para ella: es oyente desde la meditación y el estudio; servidor humilde de su propio dinamismo ${ }^{34}$. Con Él que se hace pan, y por eso la Eucaristía activa en el sacerdote el sedimento de la caridad pastoral depositado el día de su ordenación. Y así: "Cuando el presbítero identificado con Cristo dice esto es mi cuerpo, es decir, esta es mi persona que se entrega por vosotros, denota una cosa y connota otra. Denota al cuerpo de Cristo, pero connota a su propia persona, la persona del cura que se entrega por su comunidad $»^{35}$.

Ya había dicho Juan de Ávila que el sacerdote en el altar también se ofrece a sí mismo, hacienda y honra y la misma vida, hasta hacerse semejante a Cristo, hasta configurarse con el Buen Pastor, pues quien le imita en el oficio lo imite en los gemidos, ya que Él fue sacerdote y sacrificio: «Él fue el que ofreció y lo que ofreció fue» ${ }^{36}$.

Y resulta que, si el sacerdote que celebra la Eucaristía vive con fe el diálogo de amor con el Padre que se desarrolla en la plegaria eucarística, se cristifica. Se cristifica hasta el punto de que no sean dos, sino que se cumpla lo que dice S. Pablo: Qui adhaeret Deo, unus spiritus est.

Ricardo Blázquez recuerda: «La Iglesia a través del ministerio de los sacerdotes, presenta a Dios el sacrificio de Jesús, que Él mismo depositó en sus manos. La Misa es el sacrificio del Señor y de la Iglesia, presidida por los sacerdotes, como fuente permanente de misericordia de Dios y de paz entre los hermanos. Por lo dicho, se comprende que sea la Eucaristía la expresión y realización más alta de la caridad pastoral $»^{37}$. El sacerdote, por tanto, debe mirarse a la luz del amor de Dios hecho regalo en la Eucaristía. «Y es que en la santísima Eucaristía se contiene todo el bien espiritual de la Iglesia... Por lo cual la Eucaristía aparece como la fuente y la culminación de toda la predicación evangélica» (PO 5).

La Eucaristía es la expresión y realización más alta de la caridad pastoral y culminación de toda la predicación evangélica. Por eso, desde la Eucaristía, el sacerdote debe alimentar su ministerio, pues en ella reside el mismo Señor, fuente de todas las gracias, y ella es el camino para llegar a ser uno con Dios: uno con el Padre que nos da al Hijo; uno con el Hijo que se entrega como palabra y pan, sacerdote y víctima; uno con el Espíritu que lo hace presente en el altar, co-

33. Tratado sobre el sacerdocio, n. ${ }^{\circ} 10$.

34. A. CRESPO Hidalgo, Teología y espiritualidad del presbítero diocesano secular en la España del postconcilio, Málaga 1992, 327.

35. URIARTE, O.C., 65.

36. Juan I, 16, 4733s.

37. R. BlÁzquez, Eucaristía y Caridad Pastoral, CEC, Madrid 2000, 67. 
mo un día lo hiciera en el seno de María. A esta entrega y misión ha de llevarnos la mirada a Dios que se hace presente en la Eucaristía. Porque la Eucaristía nos prepara y fortalece para la Misión. Más, la Eucaristía nos envía a la Misión.

Qué bien entendió esto el Sínodo de 2005 que puso en su mismo título la palabra misión: «La Eucaristía Fuente y Culmen de la Vida y de la Misión de la Iglesia». Y Benedicto XVI, en la exhortación postsinodal: Sacramentum Caritatis, escribe: «No podemos guardar para nosotros el amor que celebramos en el Sacramento. Éste exige por su naturaleza que sea comunicado a todos. Lo que el mundo necesita es el amor de Dios, encontrar a Cristo y creer en Él. Por eso la Eucaristía no es sólo fuente y culmen de la vida de la Iglesia; lo es también de su misión: 'Una Iglesia auténticamente eucarística es una Iglesia misionera'... Así pues, el impulso misionero es parte constitutiva de la forma eucarística de la vida cristiana» (84).

\section{Y DESPUÉS LOS PRÓJIMOS}

Después a los prójimos, y el presbítero además de contemplar al Pastor ha de atender al rebaño. $Y$ el primero que pertenece a esa grey es quien la pastorea en nombre de Cristo. Por tanto, la mirada del pastor ha de recaer sobre los otros pastores que como él también han sido elegidos. Si él ha de conducir las ovejas, velar sus pasos, hallar pastos abundantes y fuentes tranquilas, sus compañeros pastores también; más aún, cuando encuentre a la oveja perdida, con ellos compartirá su alegría. Por todo esto, el pastor ha de conocerse a sí mismo y tener sentido de pertenencia diocesana y presbiteral. Presbyterorum Ordinis, n. 8, afirma: «Los presbíteros, constituidos por la ordenación en el orden del presbiterado, se unen todos entre sí por íntima fraternidad sacramental». Y en el n. 14: «Porque la fidelidad a Cristo no se puede separar de la fidelidad a la Iglesia. Así, pues, la caridad pastoral pide que, para no correr en vano, trabajen siempre los presbíteros en vínculos de comunión con los obispos y los otros hermanos en el sacerdocio. Obrando de esta manera, los presbíteros hallarán la unidad de su propia vida en la misma misión de la Iglesia».

Eso es lo que llevará al Maestro Ávila a entregarse sin descanso a los sacerdotes, para quienes, según su biógrafo L. Muñoz: «Fue muy celoso, con deseos y afectos ardentísimos, de que se conociese la perfección que pide el estado sacerdotalı ${ }^{38}$.

Después a los prójimos ${ }^{39}$. Y hemos visto, como recuerda el Concilio, la importancia que tiene que los sacerdotes se ayuden mutuamente: «Los presbíteros

38. Vida, I, $3^{\circ}$, c. 20

39. Si la caridad pastoral encuentra en la Eucaristía su expresión plena y alimento supremo, el ejercicio mismo del ministerio, dice el Concilio, vivifica y guía a los sacerdotes, ya «que por todo el ministerio, que ejercen unidos al Obispo y los presbíteros, ellos mismos se ordenan 
hallarán la unidad de su propia vida en la unidad misma de la misión de la Iglesia, y así se unirán con su Señor, y, por él, con el Padre, en el Espíritu Santo, para que puedan llenarse de consolación y sobreabundar de gozo» (PO 14).

Hallarán la unidad de su vida en la misión de la Iglesia. Y esta misión no es otra que ir hasta los confines del mundo: «ld al mundo entero y proclamad el Evangelio a toda la creación» (Mc 16, 15). Id, salid para anunciar el evangelio, porque la Iglesia existe para evangelizar. Evangelizar constituye su identidad más profunda, según recordaba Pablo VI.

Id al mundo entero, y dice el Maestro Ávila que los apóstoles son los enviados por excelencia a la Misión, «porque aunque Cristo, Él solo lo podía hacer, quiso tomar ayudadores» (Sermón 81, 73); «porque este negocio de predicar las buenas nuevas del Evangelio es muy grande» (Sermón 18, 3).

Tan grande, que su fidelidad y celo lo llevan a querer embarcarse para las Misiones ${ }^{40}$. No pudo ser, pero su caridad pastoral lo empuja como misionero para cuantos lo necesitan y en todo lo que necesitan. Así, si su entrega lo lleva a acudir adonde le demandan los señores obispos, y su disponibilidad a ser predicador incansable, fundador de colegios, reformador, maestro de sacerdotes y obispos, director de almas, inventor y apóstol de las misiones populares... Se dirá de él que no se sabe si salvó más almas con sus palabras o con su caridad.

Pero su empuje, sabiduría y virtud fueron tan de largo alcance que aún sigue iluminando a la Iglesia. Sus biógrafos recuerdan una serie de santos a los que dirigió o aconsejó, y otros muchos que, aunque no le conocieron, quedaron impresionados por su vida y doctrina, dentro y fuera de España.

\section{CUARTA EXPERIENCIA}

Hablando del espíritu misionero y de la influencia del Maestro Ávila, quisiera recordar un pequeño gesto misionero de la Diócesis de Málaga. Se inició en el mes de octubre de 1952, en la apertura del curso del Seminario. El entonces obispo de Málaga, Ángel Herrera, dirigiéndose a los sacerdotes y seminaristas, dijo: «Tened a América en el corazón. El Padre Santo tiene su vista puesta en España para la gran labor de apostolado que allí se precisa. Pido no sólo oraciones, sino vocaciones para América... Nuestra diócesis tiene que ser fiel, y va a serlo a este pensamiento del Papa».

a la perfección de vida» (PO 12). Y PDV recuerda algo que todo sacerdote conoce que «la experiencia cristiana de las personas sencillas y humildes, los impulsos espirituales de las personas enamoradas de Dios, la valiente aplicación de la fe a la vida por parte de los cristianos comprometidos en las diversas responsabilidades sociales y civiles, son acogidas por el presbítero y, a la vez que las ilumina con su servicio sacerdotal, encuentra en ellas un preciso alimento espiritual».

40. Con razón dirá más tarde en la segunda Plática a los clérigos: «En ordenándoos, sois candela que habéis de dar lumbre». 
La partida de los dos primeros sacerdotes fue el 5 de diciembre de 1954. Tras este arranque, el padre espiritual, don Alberto Planas, animó a los seminaristas para que estuvieran dispuestos a ir a la misión que había emprendido la diócesis. Y don Alberto repetía una frase de Juan de Ávila: «Si somos lo que sabemos, hemos de buscar cuantos modos pudiéremos para que la gloria de Jesucristo sea ensalzada hasta los cielos y más extendida hasta los confines de la tierra y más adelante».

Al año siguiente parten otros dos sacerdotes. Y desde entonces los sacerdotes de Málaga estamos presentes en Venezuela, primero, a las órdenes de los obispos de allá, y, desde 1986, en la Misión Diocesana de Caicara del Orinoco. Gracias a los obispos de Málaga, al clero y espíritu misionero de Juan de Ávila que nos inculcaron, nuestra diócesis posee el gozo de esta pequeña fidelidad ${ }^{41}$.

\section{EL NOMBRE DE PADRE}

La caridad pastoral impregna todas las virtudes de la vida sacerdotal, dice PO. Y el documento, Espiritualidad sacerdotal y ministerio, señala: «Evoquemos algunas cualidades de este amor, como el del Buen Pastor, que está hecho de ternura y fidelidad, las dos grandes cualidades del amor del Dios de la Biblia. La ternura le brinda entrañas que, cuando se encuentran con la miseria física o psíquica, cultural o social, moral o espiritual, se tornan misericordia» ${ }^{42}$.

Sí, la caridad pastoral impregna con su amor todas las virtudes, por eso: la fe y esperanza, la fraternidad, fidelidad, abnegación, oración, humildad, pobreza, trabajo, castidad, obediencia, espíritu misionero, alegría, afabilidad, estudio y todas las demás, quedan dinamizadas por el amor y puestas al servicio de los prójimos. San Juan de Ávila decía: «Y así, el nombre de padre que a los sacerdotes damos les debe amonestar que, pues no es razón que lo tengan en vano y mentira, deben de tener dentro de sí el afecto paternal y maternal para aprovechar, orar y llorar por sus prójimos» ${ }^{43}$.

Los sacerdotes estamos llamados a amar a todos con afecto paternal, aunque sin olvidar las recomendaciones de Jesús en Mt 23, 8-11: «Vosotros, en cambio, no os dejéis llamar rabbí, porque uno solo es vuestro maestro y todos vosotros sois hermanos. Y no llaméis padre vuestro a nadie en la tierra, porque uno solo es vuestro Padre, el del cielo. No os dejéis llamar maestros, porque uno solo es vuestro maestro, el Mesías. El primero entre vosotros será vuestro servidor».

En el Simposio ya citado, «Espiritualidad del presbítero diocesano secular», Ricardo Blázquez, ante ese texto, decía: «La novedad cristiana topa con los lí-

41. L. Orellana Hurtado, Cincuenta años de cooperación entre la Diócesis de Málaga y Venezuela, Málaga 2004.

42. Espiritualidad sacerdotal y ministerio. o.c., 65.

43. Tratado sobre el sacerdocio, $n .{ }^{\circ} 39$. 
mites del lenguaje; si por necesidad de la comunicación debemos utilizar las palabras 'maestro', 'padre', 'presidente', etcétera, no olvidemos que desde Jesús han padecido una remodelación fundamental».

Ya san Agustín había descubierto la tensión que se da entre el gozo de la fraternidad y la responsabilidad del ministerio; así, comentando el salmo 126, 1, escribe: «Ea, hermanos, si queremos ser guardados bajo la sombra o protección de las alas de Dios, seamos Israel. Yo os custodio por el oficio del gobierno, pero quiero ser custodiado por vosotros. Yo soy pastor para vosotros, pero soy oveja con vosotros bajo aquel Pastor. Desde este lugar soy como doctor para vosotros, pero soy condiscípulo vuestro en esta escuela bajo aquel único Maestro».

El ministerio pastoral no nos sitúa por encima o fuera de la comunidad. Muy al contrario, sin dimitir del oficio de pastor, el sacerdote necesita ser apacentado por el mismo Cristo, único Buen Pastor.

Y los presbíteros hemos de ser los hombres de la misión y de la acogida. De la misión, porque Jesús dijo: «ld a todos los pueblos». De la acogida en caridad (porque ella es la reina); con vida de oración (porque en la oración mora su presencia y nuestra fortaleza); siendo creadores de comunión (aunque vayamos de camino); y siempre haciendo "la verdad en la caridad» (porque hemos recibido el sacramento del Orden para vivir «configurados con Jesús, Buen Pastor, y llamados a imitar y revivir su misma caridad pastoral» (PDV 22).

Ojalá caminemos de manera digna de la vocación recibida, que pedía san Pablo. Y nos acompañen siempre las entrañas de misericordia de Jesús quien «al desembarcar, vio mucha gente, sintió compasión de ellos, pues eran como ovejas que no tienen pastor» (Mc 6, 34).

El Buen Pastor que preside la capilla del Seminario de Málaga está enmarcado en una gran cruz que sostiene en sus brazos esta inscripción: Pastor bone, fac nos bonos pastores, animas pro ovibus ponere promptos.

\section{LOS MAYORES NOS RECUERDAN}

El Maestro Ávila alzó el papel a la altura del rostro, observó la tinta y esperó. No tenía prisa. ¿Cuántas cartas habría escrito? Sonrió y se dijo: «No soy hombre de tales cuentas». Sabía que sus cartas rodaban hechas copias por los lugares donde él había anunciado el Evangelio, y lo mismo ocurría con sus sermones y el catecismo que cantaban los niños... Aunque pensándolo bien él se resistió a imprimir sus escritos, no fuera que imprimiéndolos con intención de aprovechar a los que le leyesen, se les tornasen impedimento de leer otros de los que mayor erudición y santo calor pudiesen sacar.

El Maestro miró la carta y comprobó que la tinta se había secado. Dobló la hoja y con el papel en la mano recordó el día que puestos a la mesa dijo fray Luis:

-Padre Maestro, hoy no ha dejado vuestra merced piedra de la retórica sin mover. 
Lo miró y respondió:

-En verdad, no me he cuidado de eso.

Pero fray Luis no pareció creérselo y le pidió el sermón. Y él sacó de su seno una hoja, como la que ahora sostenía entre los dedos. Fray Luis la tomó, desdobló, y encontró seis renglones, sólo seis. Los miró despacio, alzó la vista y dijo:

- ¡Seis líneas y dos horas de sermón!

El Maestro recordaba cuánta caridad y entrega le había exigido el oficio de predicador.

-Y es -se dijo-, que lo primero debe ser la estima de tan alto oficio, pues predicar exige amor, amor al Verbo que cada día nos repite: Vuestro es mi corazón y mi sangre... Vuestra mi divinidad. Vuestros mis ángeles; vuestros mis santos; vuestra mi Madre bendita; vuestra la tierra y vuestro el cielo. Toda mi vida sólo ha sido la búsqueda del hombre para que se abra a la Palabra de Dios a través del aire herido de nuestras voces.

Depositó la carta en la mesa y observó la estantería repleta de libros. Después dijo como si tuviera interlocutor:

- Todas las horas de estudio no deberían tener más misión que hacer de los predicadores canalicos por los que discurra la gracia sin dificultad ni estorbo. Pues predicar el Misterio de Dios hecho Palabra, es predicar todas las cosas. Cuántas veces lo habré repetido: esta Palabra Eterna se hizo temporal. Si hubiese predicadores que esto predicasen, no habría necesidad de predicadores de otra cosa. ¿Por ventura no se encierran todas las cosas en Dios? Luego predicar a Dios encarnado será predicar todas las cosas; porque como dice san Francisco: Deus meus et omnia.

El Maestro se sentía cansado, las enfermedades pesaban lo suyo... Se levantó apoyándose en los brazos del sillón y quedó de pie ante el escritorio recordando los años de Granada y al Maestro García Arias que le pidió un espécimen de vida sacerdotal...

Respiró despacio y oró diciendo:

-Deus meus et omnia.

Y sintió que el amor divino superaba la luz de la mañana...

Pero en el espécimen de vida que envió al Maestro García Arias le decía que reservara las tardes para los prójimos, para atenderles en sus ánimas y cuerpos, porque si no gastamos la tarde en ayudar al prójimo, en las visitas a los hospitales, en la doctrina a los niños o en consolar enfermos y remediar a los pobres, no descubriremos que Dios se nos da en la caridad. Sí, el verdadero crecimiento del ánima es en la caridad. Ni por consolaciones espirituales, ni por revelaciones, ni por oración, ni por mucho padecer hemos de pensar que crecemos, si no vemos mejorar en nosotros el amor de Dios y del prójimo.

-En nosotros -repitió-. Cerró los ojos y se dijo que los consagrados debían formar una compañía que se distinguiera por su mucho amor.

Se acercó a la ventana y contempló cómo se matizaba la luz en el patio. 
-iQué luminosos son los amaneceres de mi Andalucía! -dijo. Y observó el brocal del pozo, y el tablero de claros y sombras que se pintaba bajo el emparrado. Se sentía cansado a pesar de que las mañanas le resultaban rejuvenecedoras. Las tardes no, por las tardes las fuerzas parecen postizas. Y dijo en voz alta:

-Nunca agradeceré bastante que, el bueno del padre Salmerón, me trajera de Roma permiso para celebrar ante lucem, pues muy de mañana debo tomar algo para evitar los fuertes dolores de estómago que me corroen. Señor, dijo mirando al crucificado, haced conmigo como hace el herrero: tenedme con una mano y dadme muy bien con la otra.

Volvió al sillón de madera y se sentó como si ajustara sus huesos.

-Los predicadores y confesores, muy mucho que necesitamos el amor, pues sólo es padre y madre quien tras observarse a sí mismo, contempla a Cristo crucificado y después mira a los prójimos.

El Maestro Ávila descendía del púlpito agotado y las más de las veces empapado. A pesar de todo, tras la predicación, sentábase a oír confesiones y su puerta jamás se cerró para quien deseara verle. Así fue aquel 20 de enero, cuando predicó:

-Si el Señor no bajara del monte a la llanura, ¿qué fuera de nosotros?... ¿Qué diríamos del que estuviese en poder de los turcos preso y llevasen para él rescate y no lo quisiera recibir? Que ama su cautiverio. Pues yo os certifico que, si supiésedes qué cosa es llegaros a Cristo, que no huyésedes tanto y que os diésedes más prisa por llegar a Él...

Por llegar a Él...

Estas palabras las guardaba muy dentro, pues aquel día, tras el sermón, uno de los oyentes salió dando voces, gritando sus pecados, dándose golpes y revolcándose en el barro de las calles... Según le contaron: se detuvo en la puerta de Elvira donde tenía una tienda de libros, rasgó los profanos, repartió los piadosos y siguió su camino pidiendo perdón. La chiquillería le acompañaba gritando:

- iAl loco, al loco!

El Maestro Ávila, que aún se impresionaba con el recuerdo, dijo:

- Hasta que algunas buenas personas, compadecidas, me lo trajeron.

Cerró los ojos mientras rememoraba que había oído con interés creciente a aquel misterioso personaje.

-Lo apacigüé y me pareció estar ante la luz del camino de Damasco. Sentí que la voz del Señor lo llamaba. Mas el pastor que atiende a sus ovejas tiene que actuar como león que ruge. ¿Sería la luz de Damasco la que llamaba al vendedor de libros? El pastor ha de velar porque el alma no yerre su camino y vea visiones donde sólo hay sombras. Así que le aconsejé que marchara al Hospital Real y que, desde dentro, conociera a los enfermos y tarados para encontrar el modo de mejor servirles, y que luego Dios diría... Hízome caso y pude comprobar el resplandor de su fe. 
El Maestro Ávila abrió los ojos y dijo:

-¡Qué curioso, en los comienzos está toda la verdad! A lo que me parece, ésta es la música de Dios. Y el loco de Granada se mantuvo en el camino que le señaló su primera luz, y ahora andan sus discípulos gastando su vida en los prójimos. Para mí, no nos es dado otro camino. La encarnación de los clérigos comienza con su propio género de vida. No basta que el Sacrosanto Concilio mande a los curas parroquianos que prediquen el Evangelio. No basta eso. Ya lo dije en mi primer Memorial. ¿Cómo van a predicar, si los más de ellos no entienden el Evangelio? Sí, la encarnación se inicia con el propio género de vida, pues el pastor ha de ser primero ejemplo y después palabra. Y todavía más, ha de tener ciencia y claridad para que la verdad salga sin pérdida.

Juan de Ávila miró hacia el crucificado y lo contempló mientras exclamaba:

- ¡Ay, Señor, tú en la cruz eres la mayor palabra, pues en ella tienes la cabeza baja para oírnos y llamarnos, los brazos clavados para irnos dando tu sangre a lo largo de tus llagas, tienes el corazón abierto para entrarnos dentro de ti y que nunca nos apartemos de tu casa, tienes los pies clavados para esperarnos!

Y quedó contemplando la Cruz hasta perder la noción del tiempo. Cuando recobró conciencia dijo:

-Viva yo, ya no yo; mas viva en mí Cristo, y Cristo crucificado, apasionado, desamparado, y en sólo Dios recibido. Este Cristo quiero, aquí lo busco y fuera de aquí no lo quiero...

El Maestro bajó los ojos y los posó sobre la carta que dejó en la mesa.

-El buen sacerdote se ha de hacer niño con los niños, enfermo con los enfermos y aldeano con los aldeanos - dijo.

Y recordó que su preocupación por los niños le llevó a componer un Catecismo con «avisos para gloria del Señor y mejor enseñar la Doctrina Cristiana», donde recordaba que el que ha de enseñar la doctrina ha de ser muy humilde, manso, benigno y amoroso, y debe mostrar mucha alegría con todos; porque para tratar con niños débese acomodar, en cuanto pudiere, a sus condiciones.

Por ahí se inicia nuestra encarnación -pensó-. Y recordó que el Catecismo lo había escrito en verso sencillo y pegadizo, para que los niños lo aprendiesen y cantasen mejor. El Maestro alzó la cabeza y recitó los versos del quinto misterio de gloria:

-Con gran regocijo / se os da la corona

que debe tal Hijo / a tan noble persona.

El cielo os pregona / por Madre de Dios.

¿Quién en el mundo / tal como vos?

¿Quién en el mundo / tal como vos? -repitió y sintió una viva ternura. Suspiró despacio y rezó:

-Señora Madre, echad raíces en mis hijos.

Se rehizo de nuevo en el sillón buscando alivio. Le dolían todos los huesos, sobre todo los de los hombros, manos, rodillas y cintura. Por eso, siempre que 
los padres de la Compañía le pedían que marchara con ellos, él les remitía a sus muchos dolores y enfermedades. Los achaques estaban a la vista, pero él no podía responder con una simple negativa, pues muchos de sus hijos estaban encontrando acomodo entre los de la Compañía. Desde luego, su sitio estaba donde siempre, junto al clero diocesano que se hallaba más a la intemperie. Él tenía que permanecer, si quería ser fiel a la ley de la encarnación, como tantos de sus hijos que trabajaban a las órdenes de los prelados.

El Maestro pensó en los suyos y pareció rezumar alegría. Recordó que, bien pronto, se le juntaron más de veinte en el Alcázar viejo. Y recordó a Bernardino de Carleval, tan impulsivo e inquieto que siempre pecaba por carta de más. Y a Hernán Núñez y Hernando de Vargas el que escribiera que no le olían las manos a dineros. $Y$ al Padre Centenares que se estableció en Sierra Morena para asistir a aquellos colmeneros. Y al Padre Alonso de Molina, que se unió al anterior y entre los dos edificaron siete iglesias y pusieron ermitas de dos en dos leguas, con el Santísimo Sacramento y pila bautismal...

Se llevó la mano a la cara: el dolor parecía corrérsele hacia los ojos. Le habían asegurado que si aquel dolor fuese a más, iría a hacérsele catarata. Sostuvo la mano sobre los ojos y cuando la retiró, vio la pared y el ovillo hincado con clavos, en el que reunía los títulos de las personas y de las ciudades de donde le escribían.

Dejó de pensar en sus hijos y se acordó que debía carta a don Pedro Guerrero. Le recordaría que los predicadores llevaran a los pueblos algunos rosarios de cuentas y libros devotos y algunas cartillas para que las den a los pobres de los pueblos, para que recen y lean.

-Para que recen y lean que ese y no otro es el mal. Y para remediar tan gran mal me he gastado, y por la formación de los formadores me gastaré, y si mi Señor me ayuda tengo que morir con ese deseo -Tolle et lege, se dijo a sí mismo-.

- Los colegios han sido mi calvario, exclamó.

Y se acordó del llamado de Santa Catalina, para sacerdotes teólogos, en Granada, y de los de Cazorla, Andújar, Alcalá de Guadaira, Palma del Río, Úbeda, Baeza, Jerez, donde él mismo debió impartir lecciones a los niños.

Al Maestro Ávila se le escapó un suspiro, tomó el papel que había dejado sobre el escritorio y lo sostuvo en el aire. Era una carta para el que fuera médico del Emperador Carlos, el Doctor Pedro López que le había pedido ordenar la vida bajo su dirección, y él le decía que estando en Córdoba el P. Francisco Gómez, ya no hacía él falta para consejos. 